\title{
Evaluation of Cytomorphologic Changes of Oral Mucosa and Copper Level of Saliva in Occupationally Copper Exposed, Oral Squamous Cell Carcinoma and Normal Population
}

\author{
Torabinia Nakisa*1, Aghakouchakzadeh Arezoo ${ }^{2}$, Kargahi $\mathrm{Neda}^{1}$ and Motamedi Alireza ${ }^{3}$ \\ ${ }^{1}$ Department of Oral and Maxillofacial Pathology, Dental Materials Research Center, School of Dentistry, Isfahan University of Medical Sciences, Isfahan, Iran \\ ${ }^{2}$ Department of Oral and Maxillofacial Pathology, Oral Pathology Resident, School of Dentistry, Isfahan University of Medical Sciences, Isfahan, Iran \\ ${ }^{3}$ Department of Oral and Maxillofacial Pathology, Dental Research Center, School of Dentistry, Isfahan University of Medical Sciences, Isfahan, Iran
}

*Corresponding author: Nakisa T, Department of Oral and Maxillofacial Pathology, Dental Materials Research Center, School of Dentistry, Isfahan University of Medical Sciences, Isfahan, Iran, Tel: 00989133254025; E-mail: torabinia@dnt.mui.ac.ir

Received date: February 18, 2019; Accepted date: February 26, 2019; Published date: March 02, 2019

Copyright: @ 2019 Nakisa T, et al. This is an open-access article distributed under the terms of the Creative Commons Attribution License, which permits unrestricted use, distribution, and reproduction in any medium, provided the original author and source are credited.

\begin{abstract}
Introduction: Oral Squamous Cell Carcinoma (SCC) involves half of the oral cavity malignancies. It is very important to find the etiologic factors of oral SCC and its early diagnosis. Copper is one of the most useful metals that have been used by men since ancient time. The level of copper increases when the cancerous changes occur in the body, saliva analysis can be used to discover various illnesses because of its non-invasive methods. In addition to biopsy, an alternative method for examining oral lesions is exfoliative cytology. The aim of this study was to determine the salivary copper level and cytomorphologic changes of oral mucosa among three study groups.

Materials and Methods: In this cross-sectional study, 15 individuals with oral SCC, 15 workers exposed to copper and 15 healthy individuals were included. Saliva samples were collected and analyzed by Atomic Absorption Spectrophotometer. The exfoliative smears were prepared by brush biopsy and stained by Papanicolaou and AgNOR staining methods. Data were analyzed by One-way ANOVA and Kruskal-Wallis test. P value $<0.05$ was considered significant.
\end{abstract}

Result: The results showed a significant difference in mean salivary copper $(P=0.008)$, cytomorphology of oral mucosa and AgNOR among the three groups $(P<0.001)$.

Conclusion: Occupational exposure to copper increases the salivary levels of this element and causes changes in mucosal cells. Since this increase in is very high salivary level of copper and nuclear activity are in oral SCC patients, exposure to copper should be considered an important risk factor for oral mucosal changes.

Keywords: Copper; Cytology; Saliva; Silver nitrate staining; Squamous cell carcinoma

\section{Introduction}

Head and neck SCC, which involves oral cavity, oropharynx, and hypopharynx, is the fifth most commonly occurring cancer in the world and is one of the most frequent of death in humans [1]. SCC usually arises from a dysplastic mucosa, and the criteria for dysplasia and early invasive SCC grading are still debatable [2]. Several etiologic factors have already been identified for SCC, including use of tobacco (smoking and non-smoking), occupational exposure, environmental pollutants, dust and particles of metals, sunlight, vitamin deficiencies, hot foods, bacterial and viral infections, etc. [3,4]. Several studies have investigated the role of occupational exposures in the occurrence of head and neck cancer [5].

Copper is one of the most useful metals, mined and worked by men since ancient time, because of its essential use in various spheres of life [6]. The level of copper increases significantly when the cancerous changes occur in the body. Ceruplasmin of serum, which is the main protein of copper, rises four to eight times during malignancy [7]. Workers exposed to melting, welding, cutting, or casting copper are also involved with this element [8].

Recently, there has been growing interest in saliva analysis due to its simple and non-invasive collection methods. Oral fluid sampling is safe for the operator and patient and has easy and low-cost storage [9].

These days, exfoliative cytology is an alternative method for examining oral lesions; this simple, non-invasive and inexpensive method that can be used to conveniently identify biomarkers in laboratories is routinely done in medical and dental offices, which may increase the early diagnosis of oral mucosal malignancies in clinical trials [10]. Surface epithelium cells have nuclei; therefore, changes in these cells can be saved in nuclei and it would be a real marker for dysplastic or neoplastic changes [11].

Papanicolaou (PAP) staining is a common method used for cytology analysis, and allows for the identification of primary inflammation, dysplastic, or malignant changes [12].

Over time, the ability of other staining methods and markers to enhance the reliability of exfoliative cytology has been investigated; 
Citation: Nakisa T, Arezoo A, Neda K, Alireza M (2019) Evaluation of Cytomorphologic Changes of Oral Mucosa and Copper Level of Saliva in Occupationally Copper Exposed, Oral Squamous Cell Carcinoma and Normal Population. J Cytol Histol 10: 533. doi: $10.4172 / 2157-7099.1000533$

Page 2 of 5

one of which is silver nitrate staining (AgNOR) [13]. This technique uses Nuclear Organizer Regions (NOR) as an indicator for diagnosis of various cancers [14]. These particular portions of DNA are associated with non-histone, argilophilic, and acidic proteins [15]. NORs are seen as black spots on the nucleus by staining under the optical microscope [16]. Given the close relationship between NORs and cellular activity, the size and number of NORs can reflect or predict cell proliferation, transformation, or malignancy [17]. Malignant tumor cells show large numbers per nucleus along with small size, scattered distribution, and an irregular shape of AgNOR. However, a small number of AgNORs per nucleus as well as large size, clustered distribution, and roundness are observed in benign tumor cells [18].

The aim of this study was to determine the level of salivary copper and cytomorphologic changes of oral mucosa in patients with oral SCC, healthy people and people with occupational exposure to copper.

\section{Materials and Methods}

This study has been approved by research and ethics committee of Isfahan University of medical sciences by No: 396089.

In this cross-sectional study, 15 individuals with oral cancer, 15 workers exposed to copper (workers of the copper melting factory who had at least 5 years of work experience) and 15 healthy volunteers in dental school (control group) were included. The participants were asked to wash their mouth with a physiological serum before starting saliva collection. Then, each individual sat in a comfortable position starting the saliva collection with open eyes, bending slightly forward, and evacuating $5 \mathrm{ml}$ of saliva in the test tube. The specimens were then stored at $-20^{\circ} \mathrm{C}$ and sent to the lab for evaluation of salivary copper. After oral examination, using a disposable cytobrush on the mucosa (in the healthy group and workers, from buccal mucosa and oral SCC from the lesion area), the cell sample were collected and transferred to a clean and dry slide. The specimens were fixed immediately before drying by Pathofix spray (Iran's antibacterial medicine company), which contains $95 \%$ ethanol. Then, the slides were stained separately by PAP and AgNOR.

Saliva samples were analyzed by Atomic Absorption Spectrophotometer, and the results were expressed as micrograms per liter $(\mu \mathrm{g} / \mathrm{L})$. The PAP stained slides were analyzed under a microscope (Olympus BX41TF, Tokyo, Japan) at $(\times 100)$ magnification, and the parameters mentioned in the smears were analyzed and grouped. The parameters analyzed in the smears by PAP stain included large nuclei, nuclear changing in size and shape, pleomorphism, nuclear borders, nucleus to cytoplasm ratio, number of nuclei, and hyperchromatism. Dysplastic changes were registered and grouped in sequence:

- Class I: Normal

- Class II: Atypical

- Class III: Indeterminate

- Class IV: Suggestive of cancer
- Class V: Positive for cancer [19].

Then, the AgNOR stained slides were evaluated for NOR count. In each slide, several cells were explored at $(\times 100)$ magnification, and one cell was randomly selected. The brown-black spots in the nucleus were counted. The interconnected and nucleolus points were considered as one point. The areas of necrosis, severe inflammation, and artifacts were not calculated [20]. Data were analyzed by One-way ANOVA, Tukey's test, Kruskal-Wallis test, Mann-Whitney test, and $\mathrm{P}$ value $<0.05$ was considered significant.

\section{Results}

One-way ANOVA showed a significant difference in mean salivary copper $(\mathrm{P}=0.008)$ and AgNOR $(\mathrm{P}<0.001)$ among the three groups (Table 1 and Figure 1). Tukey's test showed that the mean amount of copper was significantly higher in the workers' saliva workers than those with oral cancer $(\mathrm{P}=0.001)$, and it was significantly higher in oral SCC patients than control group $(\mathrm{P}=0.04)$. The average number of AgNOR was significantly higher in oral SCC patients than workers $(\mathrm{P}<0.001)$ and was significantly higher in workers than control group $(\mathrm{P}<0.001)$ (Figure 1).

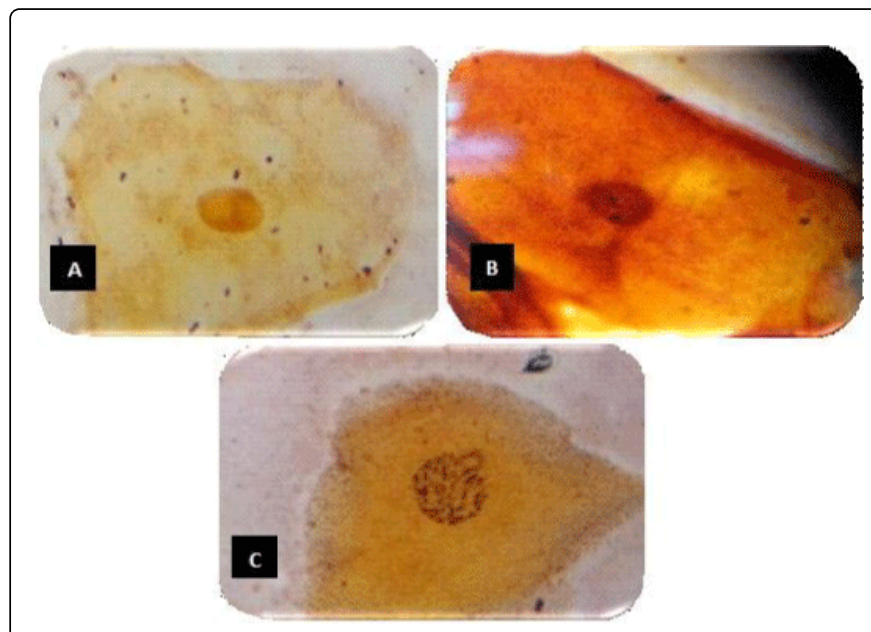

Figure 1: AgNOR stain $(\times 100)$ A: control group, B: worker, C: oral SCC patient.

Kruskal-Wallis test showed that cytomorphology of oral mucosa was significantly different between the three groups $(\mathrm{P}<0.001)$. To compare the cytomorphology of oral mucosa between two groups, Mann-Whitney test was used. This test showed that oral mucosal cytomorphology was significantly higher in people with oral SCC than in workers $(\mathrm{P}<0.001)$ was significantly higher and workers than in control group $(\mathrm{P}<0.001)$ (Tables 1, 2 and Figure 2).

\begin{tabular}{|l|l|l|l|l|l|l|l|}
\hline \multirow{2}{*}{ Variable } & \multicolumn{2}{l|}{ Control group } & Worker & \multicolumn{3}{l|}{ Oral SCC patient } & P-value \\
\cline { 2 - 8 } & Average & Standard deviation & Average & Standard deviation & Average & Standard deviation & \\
\hline Average salivary copper & $31 / 5$ & $7 / 8$ & $1215 / 5$ & $483 / 4$ & $143 / 3$ & $32 / 7$ & $0 / 008$ \\
\hline
\end{tabular}


Citation: Nakisa T, Arezoo A, Neda K, Alireza M (2019) Evaluation of Cytomorphologic Changes of Oral Mucosa and Copper Level of Saliva in Occupationally Copper Exposed, Oral Squamous Cell Carcinoma and Normal Population. J Cytol Histol 10: 533. doi: $10.4172 / 2157-7099.1000533$

Page 3 of 5

\begin{tabular}{|l|l|l|l|l|l|l|l|}
\hline AgNOR count & $9 / 1$ & $0 / 8$ & 4 & $1 / 8$ & $8 / 8$ & $1 / 4$ & $<0 / 001$ \\
\hline
\end{tabular}

Table 1: Average salivary copper with $\mu \mathrm{g} / \mathrm{L}$ and AgNOR count in three groups.

\begin{tabular}{|c|c|c|c|c|c|c|c|}
\hline \multirow{2}{*}{$\begin{array}{l}\text { Class of } \\
\text { cytomorpholo } \\
\text { gy of oral } \\
\text { mucosa }\end{array}$} & \multicolumn{2}{|c|}{ Control group } & \multicolumn{2}{|l|}{ Worker } & \multicolumn{2}{|c|}{ Oral SCC patient } & \multirow[t]{2}{*}{ P-value } \\
\hline & Number & Percent & Number & Percent & Number & Percent & \\
\hline I & 15 & 100 & 5 & $33 / 3$ & 0 & 0 & \multirow{5}{*}{$<0 / 001$} \\
\hline II & 0 & 0 & 4 & $26 / 6$ & 0 & 0 & \\
\hline III & 0 & 0 & 6 & 40 & 0 & 0 & \\
\hline IV & 0 & 0 & 0 & 0 & 0 & 0 & \\
\hline V & 0 & 0 & 0 & 0 & 15 & 100 & \\
\hline
\end{tabular}

Table 2: Frequency distribution of oral mucosa cytomorphology classes with Papanicolaou staining in three groups.

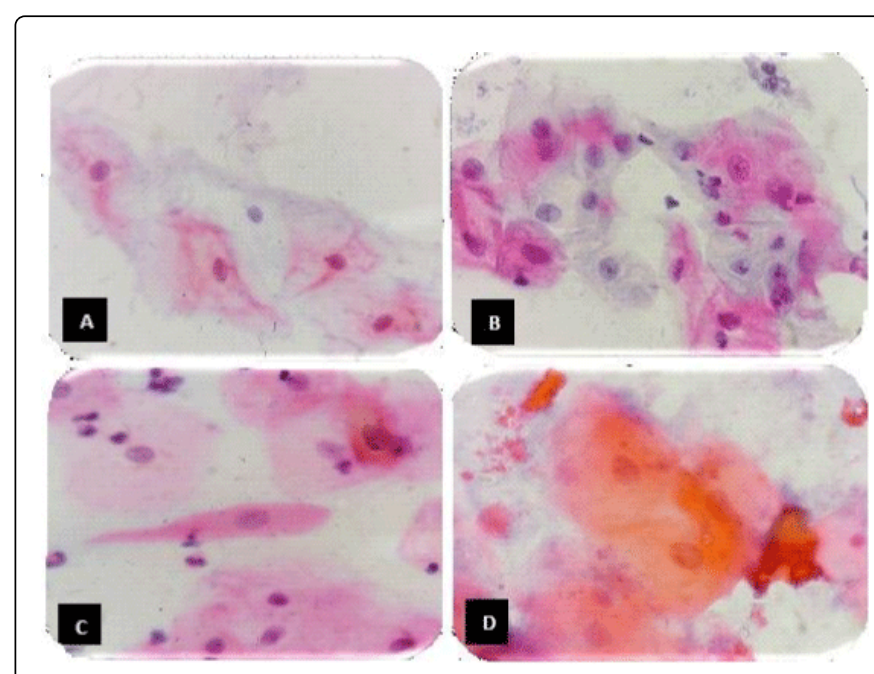

Figure 2: PAP stain (100) A: Normal cells (Class I), B: Atypical cells (Class II), C: Indeterminate cells (Class III), D: Positive for cancer (Class V).

\section{Discussion}

Oral SCC involves half of the oral cavity malignancies and is one of the major health problems in the developing countries that lead to death [21].

Several factors play a role in the development of oral SCCs, including lifestyle and environmental factors. However, efforts have been made by clinical epidemiologists to illustrate the link between malignancies and scarcity or excessive presence of rare elements [22].

Some evidence and studies have shown that long-term exposure to an average amount of copper, as in various occupational environments, affects the health of people. Moreover some studies have reported a positive relationship between copper levels in the serum, saliva and malignancy outbreak $[23,24]$.

In this study, the copper level in saliva and cytomorphological changes in the oral mucosa of subjects with occupational exposure to copper in comparison with healthy peoples and those with oral cancer were evaluated using exfoliative cytology and AgNOR staining.

The salivary copper level in this study showed a significant difference between the three groups. It was 1215.5 in the workers, which was higher than normal and oral SCC patients. However, it was higher in the people with SCC 143.3 than healthy individuals 31.5.

Several studies have investigated the serum copper level in various oral, head, and neck lesions, but few studies have examined the salivary copper level in patients.

Al-Rawi [25] reported that the salivary levels of copper and iron were higher in malignant individuals than healthy people. Ayinampudi [7] also showed a significant difference in the salivary copper level in malignant and pre-malignant oral lesions [7].

The results of this study were in line with those of the above studies, indicating that the amount of salivary copper increased when malignancy occurred. Although it cannot be argued with certainty that increase is a secondary response to malignancy changes or the patients; for some other reasons, it represents a high level of salivary copper before malignancy occurrence. This increase stimulates the proliferation of endothelial cells and plays an important role in angiogenesis, which can be effective in the malignancy process. Hence, increase in the amount of salivary copper in the workers exposed to this element needs special consideration.

The results of exfoliative cytology evaluation showed a significant difference among the three groups. The exfoliated cells in patients with SCC were classified as class V, which were positive for malignancy and showed malignant diagnostic criteria. Cellular changes in the oral mucosa of workers were significantly different from those in normal people. In this group the cells showed atypical changes (class II) and intermediate changes (class III), while in normal people all cells were normal (class I) without any changes.

In 2014, Ignacio Gonzalez Segura et al examined the relationship between Papanicolauo staining and cytomorphometric analysis in exfoliative cytology of oral mucosa and observed that these methods had high accuracy in the diagnosis of malignancy [26].

Verma, et al. [27] conducted a study to evaluate the usefulness of this method in diagnosis of oral malignant lesions and observed that assessment of changes in the nucleus and cytoplasm by cytomorphometry could be utilized as a very useful complement in diagnosis and prognosis of dysplastic lesions which could be transformed to malignancy.

The results of this study by this method were in agreement with those of previous studies. Cellular changes that have been made and their transformation from normal to intermediate and atypism can indicate the effects of copper on these cells, which requires a special follow-up despite the absence of clear tissue changes.

The mean number of AgNOR showed a significant difference between three groups. The mean number of AgNORs in oral malignant lesion was 8.8 , which was significantly higher than that of the workers 
Citation: Nakisa T, Arezoo A, Neda K, Alireza M (2019) Evaluation of Cytomorphologic Changes of Oral Mucosa and Copper Level of Saliva in Occupationally Copper Exposed, Oral Squamous Cell Carcinoma and Normal Population. J Cytol Histol 10: 533. doi: 10.4172/2157-7099.1000533

Page 4 of 5

with mean 4 . In the normal group the mean number of AgNOR was 1.9 , which was significantly lower than those of the other two groups.

In a similar study in 2014, Samadi, et al. showed the mean staining dots by AgNOR in specimens of normal mucosa, leukoplakia, and SCC increased, respectively. The results of these studies were in line with those of our study [28]. In 2017, Hitasree, et al evaluated AgNOR staining using exfoliative cytology in normal and oral squamous cell carcinoma and observed that the mean AgNOR count of each nucleus was 4.46 in the oral SCC and 2.84 in the normal mucosa, which showed a significant difference [29].

Although saliva was easily accessible and could reflect the presence of rare elements in the body in this study, salivary levels of copper were investigated using a precise method, Atomic Absorption. Since the diagnosis of dysplastic changes and suspected malignant lesions is difficult, and that sometimes there is no strong evidence to proof malignancy, evaluation of cytomorphological changes, especially the use of AgNOR staining can be helpful [30].

The results of this study and other similar studies showed that salivary levels of copper increased in the people exposed to various levels of copper due to the occupational environment, and despite the absence of any apparent changes in the tissue, the mucosal cells exhibited cellular changes. These changes consisted of class II and class III of cytomorphology classes, which were confirmed by counting AgNOR positive points and were higher than control group. An interesting point in this study was that having longer working experience and more exposure period to copper increased the amount of salivary copper and also the changes in epithelial cells. The cytology changes and the number of colored points by AgNOR were higher in these workers than the others with less work experience. This could indicate that the harmful effects of copper would increase due to the increasing duration and amount. Therefore, populations that are exposed to the particles and dust of this element require a special attention.

\section{Conclusion}

According to the results of the study, it can be concluded that occupational exposure to copper increases the salivary levels of this element and causes some changes in mucosal cells. These changes consist of nuclear activity enhancement and increase in the number of NOR in the nucleus. Since this increase is very high in salivary level of copper and nuclear activity are in oral SCC patients, exposure to copper should be considered an important risk factor for oral mucosal changes.

\section{Acknowledgement}

This study has been approved by research and ethics committee of Isfahan University of medical sciences and has been supported financially by grant No: 396089 .

The authors also would like thanks from Mr. Nasr for his kind cooperation in staining the slides.

\section{References}

1. Chan G, Tai B, Liang S, Lim D, Soo K (2002) Squamous cell carcinoma of the head and neck (HNSCC)-multi-modality treatment and impact on survival. Asian J Surg 25: 35-40.
2. Sudbø J, Bryne M, Johannessen AC, Kildal W, Danielsen HE, et al. (2001) Comparison of histological grading and large-scale genomic status (DNA ploidy) as prognostic tools in oral dysplasia. J Pathol 194: 303-310.

3. Neville BW, Damm DD, Chi AC, Allen CM (2015) Oral and maxillofacial pathology: Elsevier health sciences.

4. Rajendran R, Sellappa S (2013) Serum copper and iron levels in oral squamous cell carcinoma patients: a south Indian study. Adv Appl Sci Res 4: 203-206.

5. Carton M, Barul C, Menvielle G, Cyr D, Sanchez M, et al. (2017) Occupational exposure to solvents and risk of head and neck cancer in women: a population-based case-control study in France. BMJ open 7: e012833.

6. WEANT G (1985) Sources of copper air emissions.

7. Ayinampudi BK, Narsimhan M (2012) Salivary copper and zinc levels in oral pre-malignant and malignant lesions. J Oral Maxillofac Pathol 16: 178.

8. Armstrong CW, Moore LW, Hackler RL, Miller GB, Stroube RB (1983) An Outbreak of Metal Fume Fever: Diagnostic Use of Urinary Copper and Zinc Determinations. J Occup Med 25: 886-888.

9. Van Nieuw Amerongen A, Bolscher J, Veerman E (2004) Salivary proteins: protective and diagnostic value in cariology? Caries Res 38: 247-253.

10. Acha A, Ruesga MT, Rodríguez MJ, Martínez de Pancorbo M, Aguirre JM (2005) Applications of the oral scraped (exfoliative) cytology in oral cancer and precancer. Med Oral Patol Oral Cir Bucal 10: 95-102.

11. Montgomery PW (1951) A study of exfoliative cytology of normal human oral mucosa. J Dent Res 30: 12-18.

12. Almeida J, Cabral L, Brandão A (1994) Exfoliative cytology as a diagnostic method in stomatology. J Dent Res 73: 765

13. Mohan BC, Angadi PV (2013) Exfoliative cytological assessment of apparently normal buccal mucosa among quid chewers using argyrophilic nucleolar organizer region counts and Papanicolaou staining. Acta Cytol 57: 164-170.

14. Hammer D, Herberhold C, Pfeifer U (1998) Argyrophilic nucleolar organizer region counts in squamous cell carcinomas of the head and neck after irradiation and chemotherapy. Eur Arch Otorhinolaryngol 255: 74-76.

15. Elangovan T, Mani N, Malathi N (2008) Argyrophilic nucleolar organizer regions in inflammatory, premalignant, and malignant oral lesions: a quantitative and qualitative assessment. Indian J Dent Res 19: 141

16. Paiva RL, Sant'Ana FM, Bohrer PL, Lauxen IS, Rados PV (2004) AgNOR quantification in cells of normal oral mucosa exposed to smoking and alcohol - A cytopathologic study. Analytical and quantitative cytology and histology/the International Academy of Cytology [and] American Society of Cytology 26: 175-180.

17. Warnakulasuriya K, Johnson N (1993) Nucleolar organiser region (NOR) distribution as a diagnostic marker in oral keratosis, dysplasia and squamous cell carcinoma. J Oral Pathol Med 22: 77-81.

18. Salehinezhad J, Kalantari MR, Omidi AA, Zare R (2012) Evaluation of AgNOR Staining in exfoliative cytology of normal oral (buccal) mucosa: Effect of smoking.

19. Rao DS, Ali I, Annigeri RG (2017) Evaluation of diagnostic value of AgNOR and PAP in early detection of dysplastic changes in leukoplakia and lichen planus - a preliminary case - control study. J Oral Pathol Med 46: 56-60.

20. Crocker J, McGOVERN J (1988) Nucleolar organiser regions in normal, cirrhotic, and carcinomatous livers. J Clin Pathol 41: 1044-1048.

21. Mehrotra R, Yadav S (2006) Oral squamous cell carcinoma: etiology, pathogenesis and prognostic value of genomic alterations. Indian J Cancer 43: 60 .

22. Ramya R, Prakash S, Sudha S (2011) Assessment of serum malondialdehyde in oral squamous cell carcinoma patients and its association with tobacco habits. J Pharm Biomed Sci. 
Citation: $\quad$ Nakisa T, Arezoo A, Neda K, Alireza M (2019) Evaluation of Cytomorphologic Changes of Oral Mucosa and Copper Level of Saliva in Occupationally Copper Exposed, Oral Squamous Cell Carcinoma and Normal Population. J Cytol Histol 10: 533. doi: 10.4172/2157-7099.1000533

Page 5 of 5

23. Berman DW, Crump KS (2008) A meta-analysis of asbestos-related cancer risk that addresses fiber size and mineral type. Crit Rev Toxicol 38: 49-73.

24. Charbotel B, Fervers B, Droz J (2014) Occupational exposures in rare cancers: A critical review of the literature. Crit Rev Oncol Hematol 90: 99-134.

25. Al-Rawi NH, Talabani N (2005) Quantitative analysis of trace elements in saliva of oral cancer patients from Iraq. J College Dentistry 17: 32-35.

26. Gonzalez Segura I, Secchi D, Carrica A, Barello R, Arbelo D, et al. (2015) Exfoliative cytology as a tool for monitoring pre-malignant and malignant lesions based on combined stains and morphometry techniques. J Oral Pathol Med 44: 178-184.

27. Verma R, Singh A, Badni M, Chandra A, Gupta S, et al. (2015) Evaluation of exfoliative cytology in the diagnosis of oral premalignant and malignant lesions: A cytomorphometric analysis. Dent Res J (Isfahan) 12: 83.

28. Mansoor Samadi F, Thattil Sebastian B, Singh A, Chandra S, Mohammad $S$, et al. (2014) Silver binding nucleolar organizer regions dots in oral leukoplakia with epithelial dysplasia and oral squamous cell carcinoma: an in vivo study. ISRN dent 2014: 479187.

29. Hitasree B, Manne M, Shivani N, Afroz SA, Suri C, et al. (2017) Evaluation of Agnor staining using exfoliative cytology in oral squamous cell carcinoma. Int J Curr Res 9: 46896-46899.

30. Rajput DV, Tupkari JV (2010) Early detection of oral cancer: PAP and AgNOR staining in brush biopsies. J Oral Maxillofac Pathol 14: 52. 